\title{
Landsat 8 OLI data for identification of hydrothermal alteration zone in Singhbhum Shear Zone using successive band depth difference technique - a new image processing approach
}

\author{
Krishnendu Banerjee, Manish Kumar Jain, A. T. Jeyaseelan and Surajit Panda
}

Recent advances in calculation algorithms have led to a new level of image processing for mineral identification and mapping. Mineral outcrop mapping has a decade's history of using conventional methods like band combintion, band ratioing and relative absorption band depth (RBD) technique. Modification of these algorithms enriches the capabilities of object identification and mapping. Band combination and band ratioing help to locate the distribution of a hydrothermal altered zone. In the current study, an attempt has been made to modify the RBD approach. Newly introduced successive band depth difference (SBDD) measures the difference of reflectance values in successive bands by dividing the sum of the two highest successive shoulders by the shoulder of the lowest value before the starting shoulder. Band math function has been used in various bands of Landsat 8 operational land imager (OLI) data to access the precise distribution of points of the hydrothermal altered zone. SBDD method has achieved a kappa coefficient of 0.86 which depicts significant levels of accuracy.

Keywords: Relative absorption band depth, RGB, signal-to-noise ratio, SBDD, TIRS.

ADVANCEMENT in spectral remote sensing technologies has improved significantly over the past two decades, with the use of multispectral remote sensing data, particularly for hydrothermal mineral mapping system ${ }^{1}$. The remote sensing mineral investigation technique depends on surface composition and its absorption of energy. Various techniques process multispectral imagery to acquire surface compositional character and information on a pixel to pixel basis for the entire image ${ }^{2}$.

The commonly used algorithms include the spectral angle mapper $(\mathrm{SAM})^{3}$, spectral feature fitting $(\mathrm{SFF})^{4}$, principle component analysis (PCA), spectral binary encoding $(\mathrm{SBE})^{5}$, mixture tuned matched filtering $(\mathrm{MTMF})^{6}$, spectral absorption index $(\mathrm{SAI})^{7}$, absorption band-depth $^{8}$ and RBD analyses ${ }^{9-11}$.

Crowley et al. ${ }^{9}$ used radiance data to develop the RBD method for mineral mapping. A three-point band ratio

\footnotetext{
Krishnendu Banerjee, Manish Kumar Jain and Surajit Panda are in the Indian Institute of Technology (ISM), Dhanbad 826004 , India and A. T. Jeyaseelan is in the Regional Remote Sensing Centre West, National Remote Sensing Centre, Indian Space Research Organisation, Jodhpur 342 003, India.

*For correspondence. (e-mail: rsgis.pintu@gmail.com)
}

formulation technique was also known as $\mathrm{RBD}^{10}$. The RBD image was produced by adding and then dividing the 'absorption-band shoulders' by adjustment bands of the same channel series respectively $(\mathrm{RBD}=($ band $1+$ band 2)/band 3). Therefore, RBD images offer the depth of an absorption feature relative to 'local continuum correction' ${ }^{12}$.

This study uses modified RBD or newly introduced SBDD approach for mineral prospectivity mapping. The SBDD approach calculates the depth difference between two successive peak channels. Hence, all available Landsat 8 Operational Land Imager (OLI) bands have been analysed and integrated using these 'modification of RBD' or 'SBDD' methods for porphyry copper mineral prospectivity mapping in Singhbhum Shear Zone (SSZ) ${ }^{11}$.

\section{Landsat 8 OLI data processing}

Data-driven techniques are used for preliminary identification of hydrothermal alteration mineral zones through different colour compositions. Band ratio helps to highlight the target areas. Successive band depth difference approach and logical operators are implemented to extract 
Table 1. Band specifications of ASTER and Landsat 8 sensors

\begin{tabular}{|c|c|c|c|c|c|}
\hline Sensors & Subsystem & Band number & $\begin{array}{c}\text { Spectral } \\
\text { range }(\mu \mathrm{m})\end{array}$ & $\begin{array}{c}\text { Spatial } \\
\text { resolution (m) }\end{array}$ & $\begin{array}{c}\text { Swath } \\
\text { width }(\mathrm{km})\end{array}$ \\
\hline \multirow{11}{*}{ Landsat 8 OLI and TIRS } & \multirow{5}{*}{ VNIR } & 1 & $0.433-0.453$ & \multirow{5}{*}{30} & \multirow[t]{11}{*}{185} \\
\hline & & 2 & $0.450-0.515$ & & \\
\hline & & 3 & $0.525-0.600$ & & \\
\hline & & 4 & $0.630-0.680$ & & \\
\hline & & 5 & $0.845-0.885$ & & \\
\hline & \multirow[t]{2}{*}{ SWIR } & 6 & $1.560-1.660$ & & \\
\hline & & 7 & $2.100-2.300$ & & \\
\hline & \multirow{4}{*}{$\begin{array}{l}\text { Cirrus } \\
\text { TIRS }\end{array}$} & 8 (Pan) & $0.500-0.680$ & 15 & \\
\hline & & 9 & $1.360-1.390$ & 30 & \\
\hline & & 10 & $10.60-11.20$ & 100 & \\
\hline & & 11 & $11.5-12.5$ & & \\
\hline
\end{tabular}

Source: ASTER user handbook and Landsat 8 (18) data user handbook.

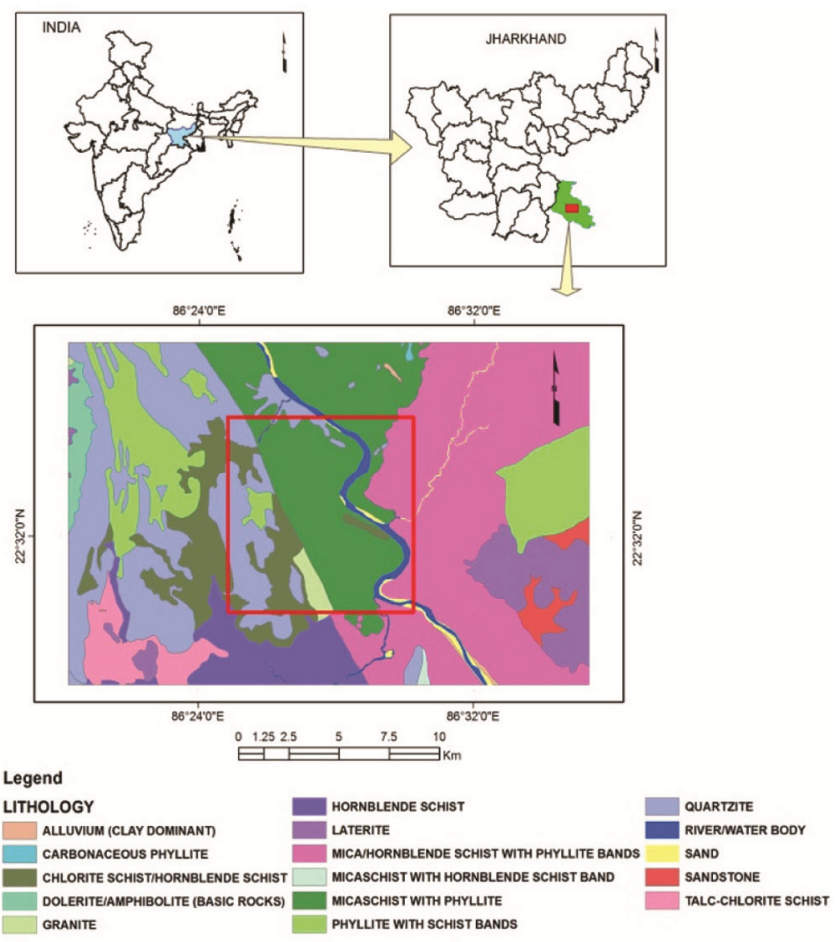

Figure 1. Location and geology of the study area.

the alteration zones. Landsat 8 OLI has been used to identify clay minerals which are characterized by absorptions features in shortwave infrared channels ${ }^{13}$. Landsat 8 covers visual to shortwave infrared spectrum channel in nine consecutive bands covering a $185 \mathrm{~km}$ swath. Eight bands have $30 \mathrm{~m}$ spatial resolution except for a $15 \mathrm{~m}$ panchromatic band as shown in Table 1 (ref. 14). Landsat $8 \mathrm{OLI}$ has the greater 12-bit quantization which makes it more preferable for mineral mapping ${ }^{14,15}$.

\section{Geological history of the study area}

The study area is located at Singhbhum Copper Belt of Jharkhand which is one of the mineral-bearing stretches of India with high potential (Figure 1). The arcuate belt stretches for over $200 \mathrm{~km}$ between Baharagora in the south-east and Duarpuram in the west. Physiographically, the area consists of ridge systems underlined by characteristic rock types such as the Dalma lava and its variants, quartzites, quartzose phyllites, etc. The area is developed on (i) Singhbhum granite in the southwest, (ii) schists on either side of the Subarnarekha valley and (iii) raised tracts of red soil which may be underlain by tertiary gravels ${ }^{16}$.

Major stratigraphic units of 'Copper Belt Thrust' suggested by Dunn ${ }^{17}$, can be separated by Iron Ore Group (including the 'Gorumahisani Group') on the south and the Singhbhum Group on the north. The major copper mineral is chalcopyrite which occurs in veins and patches associated with chlorite schist. Quartzites and granites are the siliceous rocks found in mylonitized equivalents ${ }^{18,19}$. These types of rocks are characterized by soda rich feldspars ${ }^{20,21}$. The sulphides of the shear zone are mainly associated with chalcopyrite, pyrite, pyrrhotite and magnetite $^{22}$. Chlorite and sericite quartz and biotites are found in multiple forms ${ }^{23,24}$.

\section{Preprocessing of data}

Landsat 8 image (LC81390442016317LGN00, path/row 139/44) was downloaded from the United States Geological Survey (USGS) website. This Landsat 8 OLI data was captured on 12 November 2016, which covers the entire East Singhbhum district along with the study area. The satellite image information is provided in Table 2. Preand post-processing of Landsat 8 OLI satellite data was carried out using environment for visualizing images (ENVI) version 4.8 software (Figure 2) ${ }^{25}$. Fast Line-ofSight Atmospheric Analysis of Hypercubes (FLAASH) atmospheric correction module was used for atmospheric correction. All the bands of Landsat 8 data were layer stacked and the central wavelength value was assigned to each band for further analysis. 


\section{Image processing}

\section{Band combinations}

True colour images are the composite result of three visual primary grey images. Colour images are composed of three primary colours, i.e. blue, green and red. False colour images, mainly colour infrared images, have specific advantages over true colour. While it is easy to recognize different geological units using true colour images colour infrared images also present geology quite well ${ }^{26}$. Band combinations eliminate most atmospheric attenuation like haze, back scattering, etc. Different combinations of false colour band scan highlight many features ranging from mineralogical changes to moisture changes, etc. ${ }^{27}$. The main advantage of true colour images is that it is easy to recognize units in areas where the stratigraphy

Table 2. Landsat 8 OLI image metadata information

\begin{tabular}{ll}
\hline Scene center time & $04: 37: 30.6183250$ \\
Cloud cover & $2.98 \%$ \\
Sun azimuth & 153.52916597 \\
Sun elevation & 44.92756117 \\
Pixel size $9(\mathrm{~m})$ & 30 \\
Earth sun distance & 0.9897199 \\
Map projection & UTM \\
Datum & WGS 84 \\
UTM zone & 45 \\
\hline
\end{tabular}

Source: USGS website. available at: https://glovis. usgs.gov/.

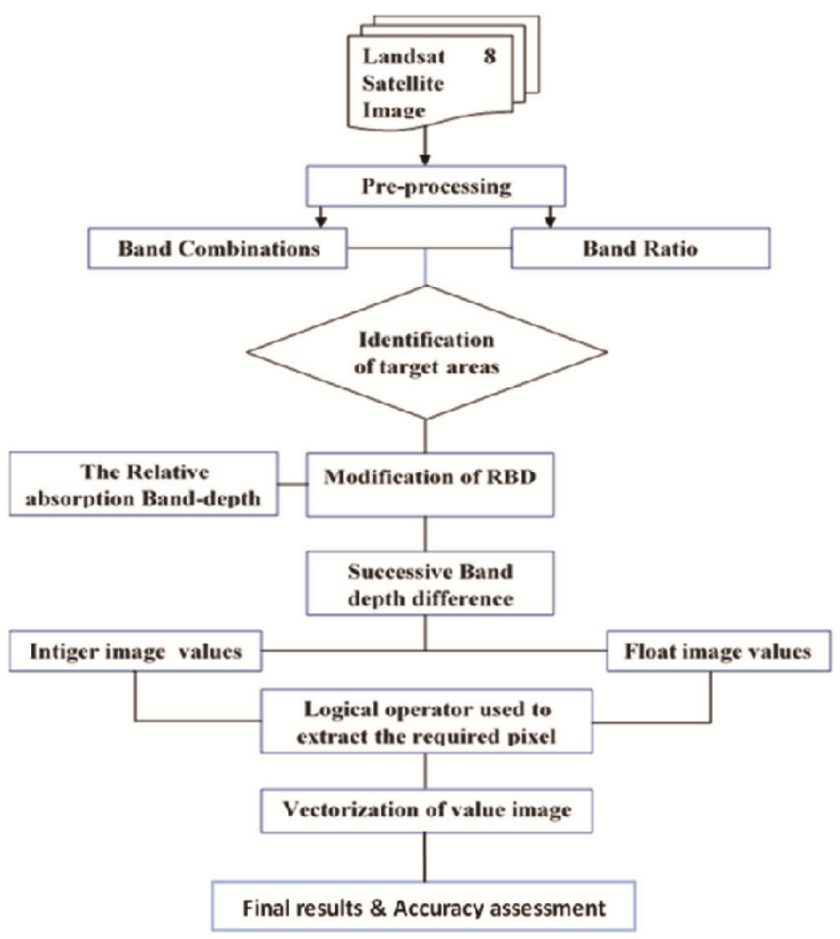

Figure 2. Methodology flow chart of Landsat 8 data analysis. is known and increase the ability of the interpreter in the identification of rock units where the geologic section is unknown ${ }^{26}$. Historical studies are the evidence of Landsat 8 OLI image capabilities, which utilize some set of band numbers for rock discrimination of alteration zones based on colour intensity variations, such as RGB of B7, B6, B4 or RGB of B5, B6, B7 (Figures 3 and 4) ${ }^{28}$. However

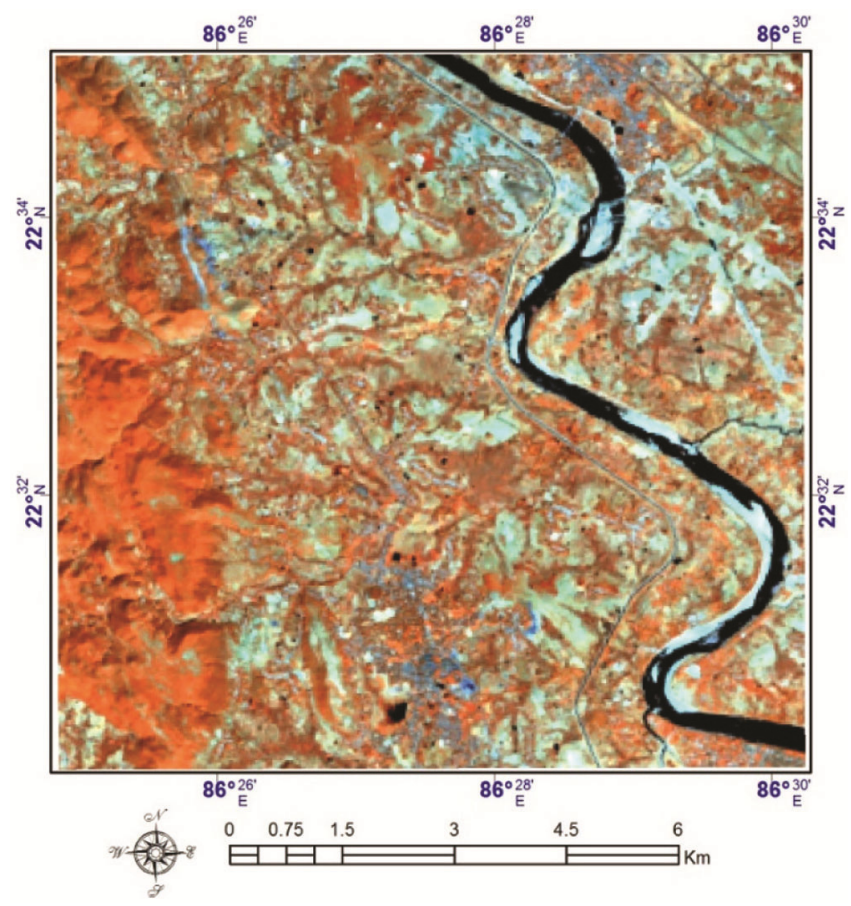

Figure 3. RGB colour combination of bands 5, 6 and 7 of Landsat 8 satellite image.

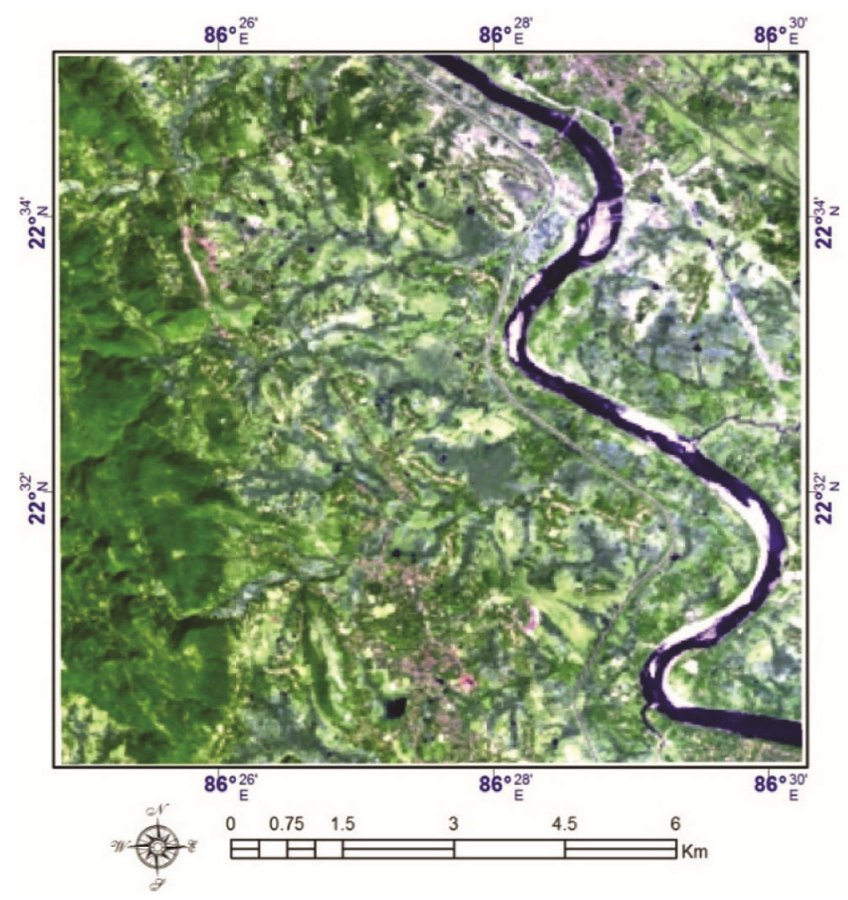

Figure 4. RGB colour combination of bands 7, 6 and 4 of Landsat 8 satellite image. 

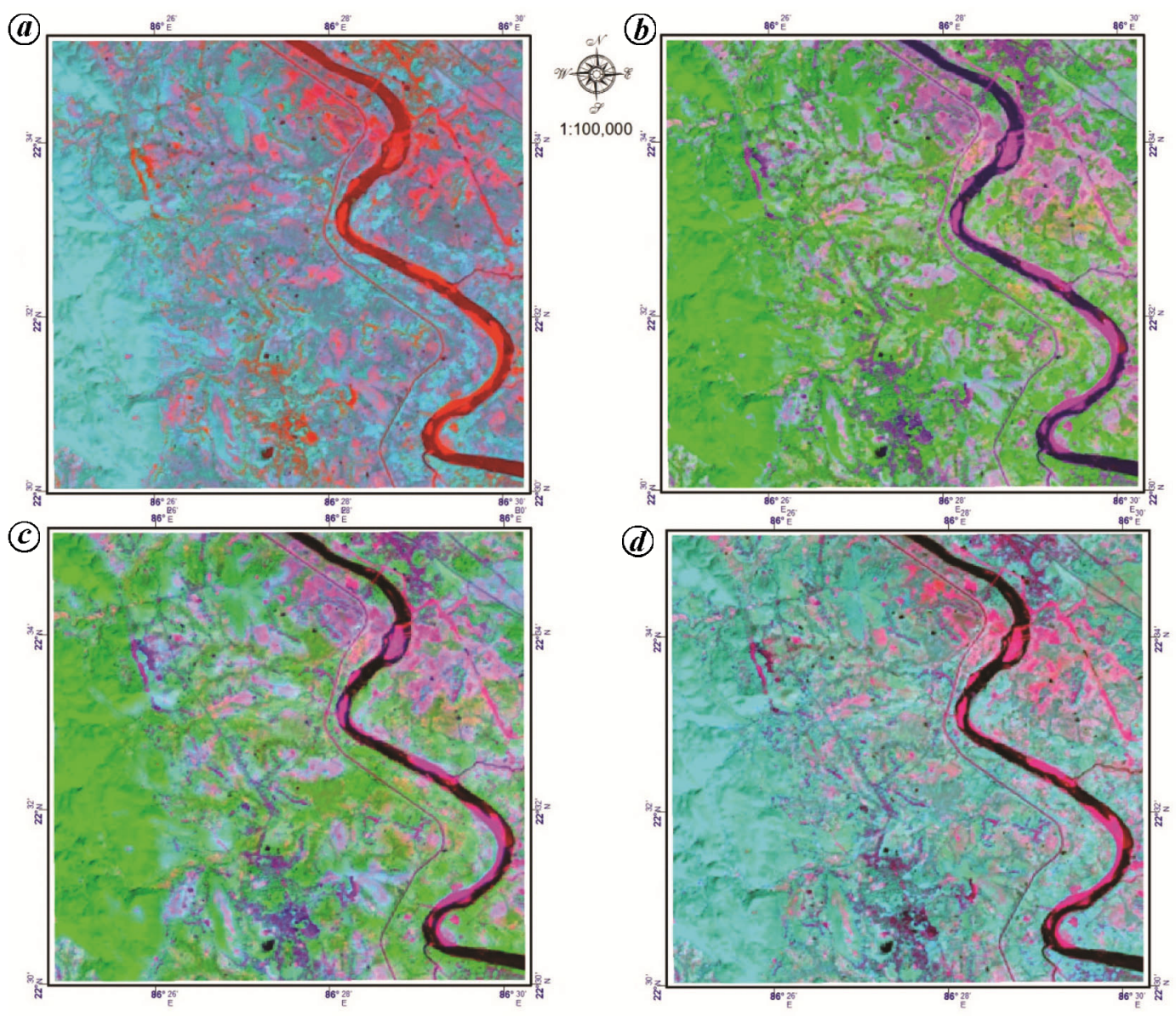

Figure 5. $\boldsymbol{a}$, Kaufman band ratio $(7 / 5 ; 5 / 4 ; 6 / 7$ as RGB). $\boldsymbol{b}$, Sabins band ratio $(4 / 2,6 / 7$ and $6 / 5$ as RGB). $\boldsymbol{c}$, Hasim band ratio (4/2,6/7, 10 as RGB). $\boldsymbol{d}$, Pour and Hasim band ratio (4/2 ,6/7, 5 as RGB).
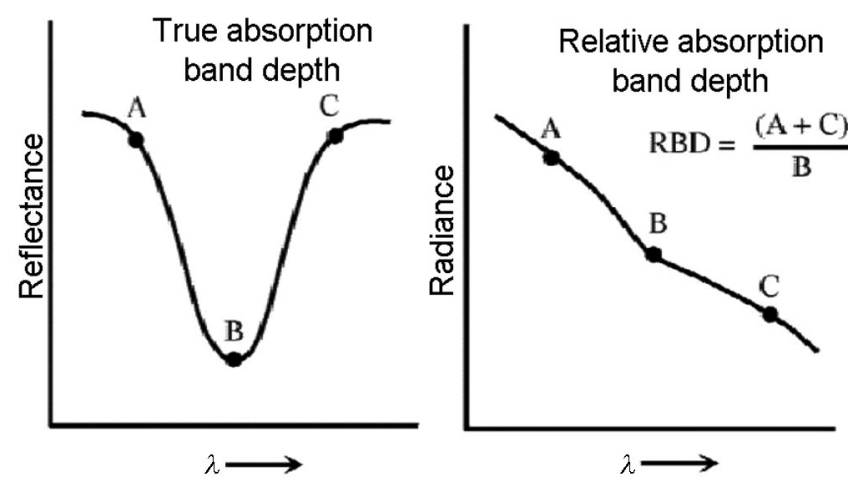

Figure 6. True and relative absorption band depth ${ }^{9,37}$.

extracting band combinations that illuminate the target litho-units are quite difficult ${ }^{29}$.

\section{Band ratio}

Band ratio can reduce the effect of environmental artefacts. Previous studies illustrated typical band ratios which have been used for enhancing lithological features ${ }^{1,13,14}$.
Most effective band ratio practices used by Sabins' for geological mapping, are RGB of 4/2, 6/7 and 6/5 (Figure 5 a). Sabins' band ratio is beneficial for lithological mapping and detection of hydrothermal alteration zones ${ }^{1,30}$. Previous studies suggest that iron-rich minerals or other minerals associated with hydrothermal processes can be delineated using $4 / 2$ of Landsat 8 OLI image ${ }^{12}$. Band ratio of Landsat 8 OLI image $6 / 7$ is beneficial for mapping clay minerals like kaolinite, illite and montmorillonite ${ }^{31}$. Ali and Pour ${ }^{30}$ suggest a combination of Landsat 8 OLI image $4 / 2,6 / 7$ and 5 as RGB for identification of lithology, altered rocks, and vegetation. Kaufmann band ratio $(7 / 5,5 / 4$ and $6 / 7)$ was also used for separation of vegetation from altered zones ${ }^{30}$. Band ratios derived from images 4/2, 6/7, 5 and 4/2, 6/7, 10 as RGB depict separability of rock units and alteration zones precisely (Figure $5 c$ and $d)^{32}$. Colour variations can be seen in different band ratio results which are the primary keys to identify a hydrothermally altered zone.

Several pair of bands have offered delineation of various rock-mineral types such as: (a) 4/2 - iron oxide, (b) 6/7 - hydroxyl bearing rock, (c) 7/5 - clay minerals and (d) $6 / 5$ - ferrous mineral ${ }^{32,33}$. 
GENERAL ARTICLES
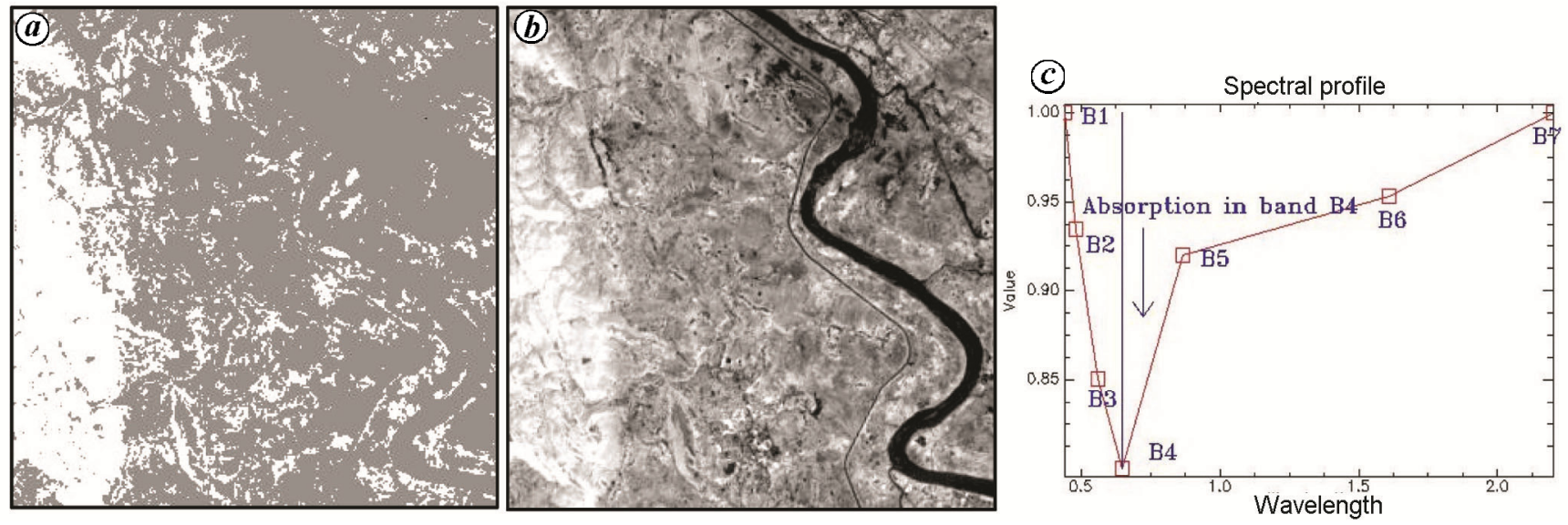

Figure 7. $\boldsymbol{a}, \mathrm{RBD}$ image $(\mathrm{b} 2+\mathrm{b} 5) / \mathrm{b} 4$ in integer value. $\boldsymbol{b}, \mathrm{RBD}$ image $(\mathrm{b} 2+\mathrm{b} 5) / \mathrm{b} 4$ in float value. $\boldsymbol{c}$, Spectral plot showing absorption band.

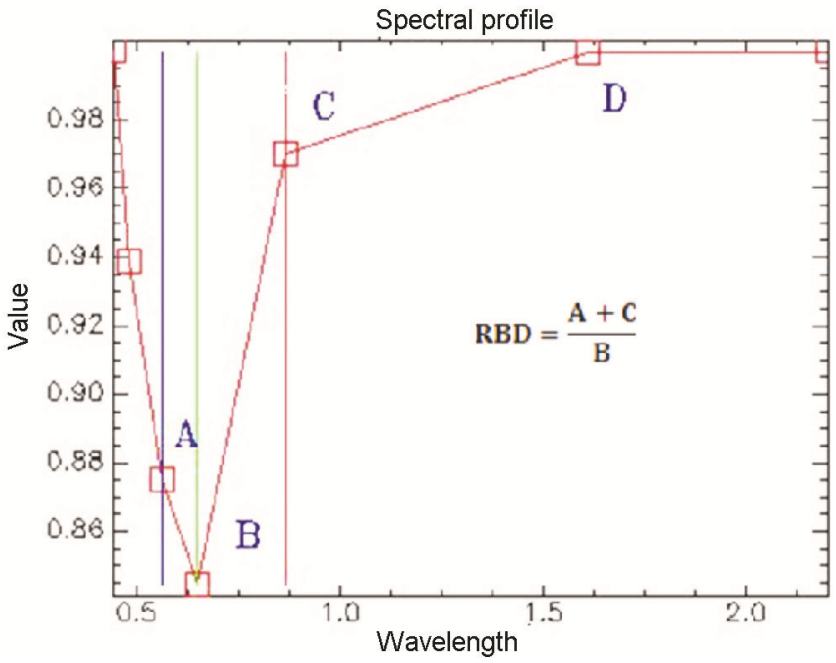

Figure 8. Band selection used in RBD approach.

\section{Relative absorption band depth method}

Band ratio, PCA and RBD are some common methods to detect hydrothermally altered zones. Band ratio suppresses the common attribute in two bands. Band ratio images are designed to highlight the spectral contrast of specific objects having absorption characteristics in the entire channel ${ }^{34,35}$. Band ratio (BR) divides one band by another to create a new image that may be used to highlight a particular type of feature ${ }^{36,37}$. RBD divides the sum of two highest reflectance spectral bands which may be in a sequence in the spectral channel or not, by the lowest absorption spectral channel (Figures 6 and 7) ${ }^{9}$. RBD images are the result of a three-point ratio formulation for displaying $\mathrm{Al}-\mathrm{O}-\mathrm{H}, \mathrm{Mg}-\mathrm{OH}$ and $\mathrm{CaCO}_{3}$ absorption strengths ${ }^{9,10}$.

RBD reduces radiometric miscalibrations which can misguide the interpreter. RBD produces a local continuum correction (LCC) which removes any small channel-to-channel radiometric offsets. RBD provides information on solar irradiance drop-off for each pixel in the dataset and irregular atmospheric absorption ${ }^{9,12,38}$. Absorption features associated with local continuum detect pixels having greater absorption bands, which indicates presence of a particular mineral ${ }^{38}$.

\section{Successive band depth difference technique}

In the present study, an attempt was made to modify the RBD approach. SBDD measures the difference in reflectance value of successive bands by dividing the sum of two highest successive shoulder channels by the bottom channel before the starting shoulder (Figure 8). Both RBD and SBDD image processing methods are used to identify lithological units as well as hydrothermally altered zones. Depth difference of two highest reflectance channels can be calculated by this method. Landsat 8 OLI data have absorption features in different band numbers which were used to analyse a specific mineral type. Chlorite and epidote have extensive $\mathrm{Fe}^{2+}$ absorption feature in the $0.66-1.65 \mu \mathrm{m}$ region ${ }^{39,40}$. Alunite and kaolinite have $\mathrm{Al}-\mathrm{O}-\mathrm{H}$ absorption features at $2.17 \mu \mathrm{m}$ and $2.20 \mu \mathrm{m}$ respectively. Muscovite has a prominent $\mathrm{Al}-$ $\mathrm{O}-\mathrm{H} \quad 2.20 \mu \mathrm{m}$ absorption feature and a secondary $2.35 \mu \mathrm{m}$ absorption feature ${ }^{39,40}$.

\section{Data analysis}

Crowley et al. ${ }^{9}$ have developed a method of RBD which was processed through radiance data. In the present study radiance data of Landsat 8 OLI was used for the image analysis and identification of hydrothermally altered zones. Layer stacking and subsetting the image of the study area was carried out. Colour variation in different band combination and ratio images confirmed the location of the hydrothermally altered zones. Depth-based image analysis of spectra needs precise pixel locations. Geological 

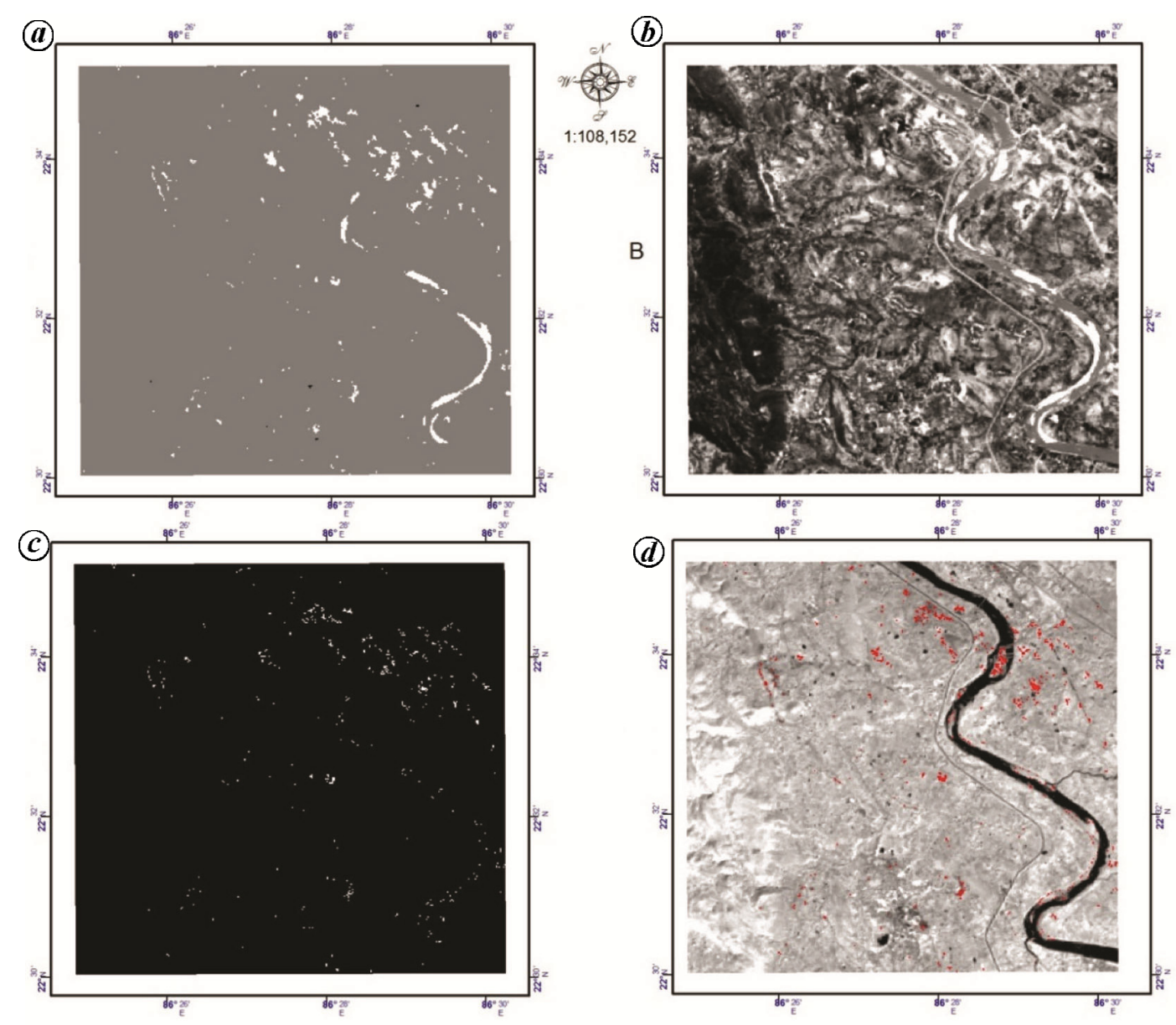

Figure 9. $\boldsymbol{a}$, Successive band depth difference image $((\mathrm{B} 7+\mathrm{B} 6) / \mathrm{B} 5)$ in integer value. $\boldsymbol{b}$, Successive band depth difference image $((\mathrm{B} 7+\mathrm{B} 6) / \mathrm{B} 5)$ in float value. $\boldsymbol{c}$, Logical operator mined exact value. $\boldsymbol{d}$, Vectorization of logical operators output image of mining area outcrop.

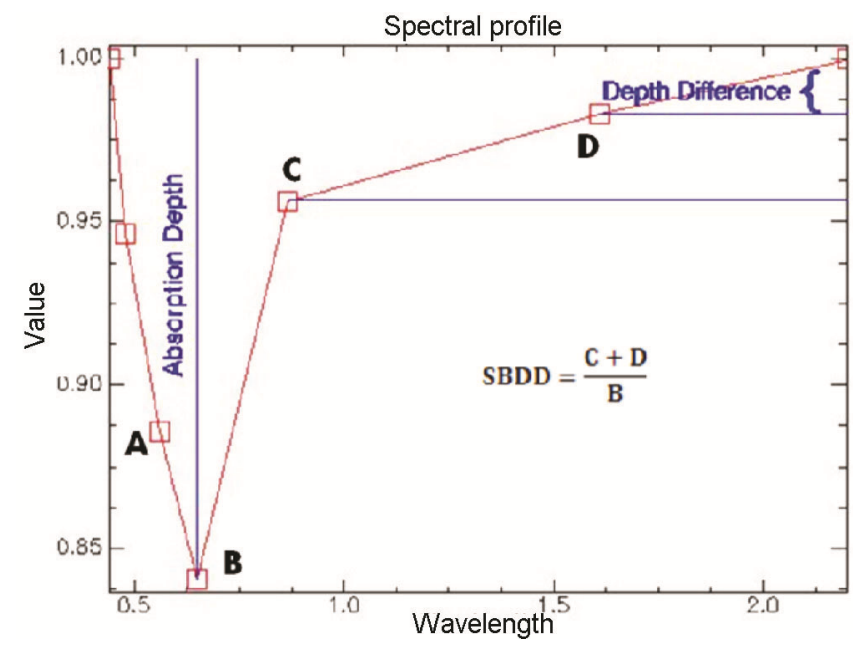

Figure 10. Band selection used in SBDD approach.

Survey of India (GSI) location points of copper have been superimposed in RGB with 5, 6, 7 bands of Landsat 8 OLI data to perceive spectral characteristics of ore outcrops for further analysis (Figure 9). Hydrothermally altered mineral shows absorption feature $(0.66 \mu \mathrm{m})$ in a known sample location (Figure 10) (11,41,42 $^{\text {. RBD approach }}$ suggests dividing the sum of two peak reflected shoulders by the lowest absorption channel between them. Local continuum removal is possible by this approach. SBDD approach calculates the depth difference between two successive peak channels (Figure 10).

Typical spectral curve (Figure 10) depicts the conceptual parameters used in the SBDD calculation. Infrared to shortwave region of the electromagnetic spectrum is most significant to iron oxides, oxyhydroxides, and clay minerals which are formed by high or low-temperature alteration ${ }^{43,44}$. A significant level of band absorption can be noticed in SWIR channels $(1.5 \text { and } 2.3 \mu \mathrm{m})^{45}$. Molecular vibrations from species such as hydroxyl, water, carbonate and sulphate are the sign of transition metals (generally iron or copper $)^{46,47}$. Electronic orbital configuration and the combined overtones of molecular vibration process are responsible for such band absorption effects in transition metals $^{30}$. Three successive bands of Landsat 8 OLI data, B5 (NIR), B6 (SWIR1) and B7 (SWIR2) have been used for the calculation. The integer and float value images 
GENERAL ARTICLES

Table 3. Accuracy assessment statistics of different mapping procedures used in multispectral image

\begin{tabular}{lcccc}
\hline Satellite image & $\begin{array}{c}\text { User accuracy } \\
(\%)\end{array}$ & $\begin{array}{c}\text { Producer accuracy } \\
(\%)\end{array}$ & $\begin{array}{c}\text { Overall classification } \\
\text { accuracy (\%) }\end{array}$ & $\begin{array}{c}\text { Overall kappa } \\
\text { statistics (\%) }\end{array}$ \\
\hline Band combination & 80.00 & 70.59 & 84.62 & 0.6395 \\
Band ratio & 73.33 & 78.57 & 86.79 & 0.6679 \\
SBDD & 93.33 & 87.50 & 94.34 & 0.8633 \\
\hline
\end{tabular}
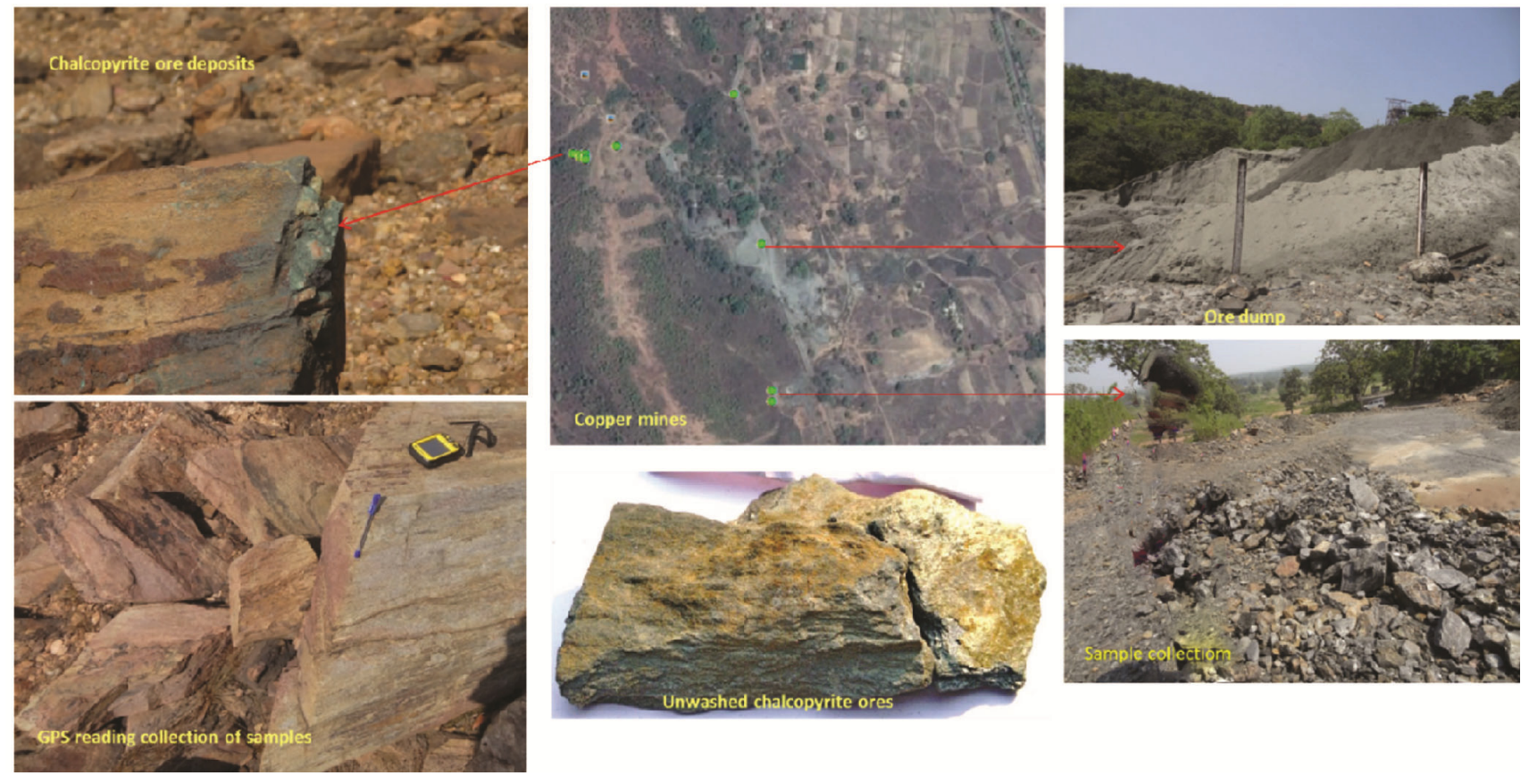

Figure 11. Sample collection and GPS surveying of study area.

of SBDD technique were processed through ENVI software's band math function using simple logical expressions. Equations are given below. SBDD of float value image was calculated using eq. (1).

$$
\text { (float (b1) + float (b2))/float (b3). }
$$

The integer value of the same was calculated using eq. (2).

$$
(\mathrm{b} 1+\mathrm{b} 2) / \mathrm{b} 3 \text {. }
$$

The integer and float value images were calculated for elimination of mixed pixel values which were nontargeted materials or non-hydrothermally altered zones. Such data values were eliminated through interactive data language (IDL) and logical operators. A critical threshold value of 2.10 was assigned in the operation (eq. (3)). The threshold value was decided after examining known points of chalcopyrite occurrence. The integer value image shows three data types 0,1 and 2 . The integer value image was compared with the float value image. ENVI software uses a typical type of conversion factor while processing the band math function for float value image. This conversion factor of ENVI facilitates the extraction of floating point difference up to 0.10 interval. The mathematical expression in eq. (3) does the same. The first operation in eq. (3) eliminates float values above 2.10 and the second operation extracts the value of 2.00. Both operations are connected through a logical 'and' operator which fetches the demanded values when both the expressions are satisfied simultaneously (eq. (3)). The value image of (2.10$2.00)=0.10$ difference can be extracted by the above procedure. The output value image provides the output in true and false value point in which true values are presented as 1 and false values are presented as 0 (Figure $9 a$ and $c$ ).

((b1 le 2.10) and (b2 eq 2)).

\section{Results and discussion}

Dark blue patches in the north-western and south corner of the study area confirm the presence of hydrothermal alteration zones (RGB 5, 6, 7; Figure 3). The second $\operatorname{RGB}(7,6,4)$ shows dark brown colour in the same areas 
(Figure 4). Sabins' ratio (4/2, 6/7 and 6/5 as RGB) helps to recognize the hydrothermally altered zones in violet colour which can be seen in the North, South and North Eastern portions (Figure $5 b$ ). Band combination of $4 / 2$, $6 / 7$ and 5; 4/2, 6/7 and 10 was suggested by Hasim et $a l .^{48}$. The result of these band ratios represents the tonal difference in vegetation, water and hydrothermally altered zones. Light and dark violet colour in RGB of $4 / 2$, 6/7, 10 (Figure $5 c$ ) and 4/2, 6/7, 5 (Figure $5 d$ ) confirm the presence of hydrothermally altered minerals in the southern and northern part of the study area (Figure $9 d$ ). Overall accuracy of band combination, band ratio and SBDD was compared. The accuracy assessment was carried out using GPS location and GSI mineral locations. Band combination and band ratio methods show 0.63 and 0.66 of kappa statistics. SBDD based porphyry copper zonation map shows $94.34 \%$ of overall classification accuracy and kappa coefficient of 0.86 (Table 3). Field verification and data collection was carried out using hand-held GPS and digital camera. Geo-tagged field photos were collected in mining areas and their surroundings (Figure 11).

\section{Conclusion}

Band combination, band ratioing and RBD approach are conventional methods used for explicit mineral identification in large scale. Field surveying methods for mineral outcrop mapping are difficult and time consuming. Different band combination and ratio images represent various colours of rock minerals and are key to mineral identification. SBDD method is a spectral depthbased method which needs prior knowledge of the targeted mineral spectra. Misinterpretation of target spectra may lead to wrong SBDD calculation. SBDD method uses radiance data of satellite image which is biased by atmospheric attenuation such as gases, dust particles, haze, etc. and hence can reduce overall accuracy.

1. Sabins, F. F., Remote sensing for mineral exploration. Ore Geol. Rev., 1999, 14, 157-183.

2. van der Meer, F., De Jong, S. and Bakker, W., Imaging Spectrometry: Basic Analytical Techniques, Imaging Spectrom, Springer, Dordrecht, 2002, pp. 17-61.

3. Kruse, F. A., Lefkoff, A. B., Boardman, J. W., Heidebrecht, K. B., Shapiro, A. T., Barloon, P. J. and Goetz, A. F. H., The spectral image processing system (Sips)-interactive visualization and analysis of imaging spectrometer data. Remote Sens. Environ., 1993, 44, 145-163; doi:10.1016/0034-4257(93)90013-N.

4. Clark, R. N., Swayze, G. A., Gallagher, A., Gorelick, N. and Kruse, F. A., Mapping with imaging spectrometer data using the complete band shape least-squares algorithm simultaneously fit to multiple spectral features from multiple materials. In Proceedings of the third airborne visible/infrared imaging spectrometer (AVIRIS) workshop, 1991, vol. 42, pp. 2-3.

5. Binzel, R. P., Rivkin, A. S., Bus, S. J., Sunshine, J. M. and Burbine, T. H., MUSES-C target asteroid (25143) 1998 SF36: a reddened ordinary chondrite. Meteorit. Planet. Sci., 2001, 36 1167-1172; doi:10.1111/j.1945-5100. 2001.tb01950.x.

6. Amin Beiranvand Pour and Mazlan Hashim, Hydrothermal alteration mapping using Landsat-8 data, Sar Cheshmeh copper mining district, SE Iran. J. Taibah Univ. Sci., 2014; http://dx.doi.org/ 10.1016/j.jtusci.2014.11.008.

7. Wang, J. N. and Zheng, L. F., The spectral absorption identification model and mineral mapping by imaging spectrometer data. Remote Sens. Environ., 1996, 1, 20-31.

8. Panda Surajit, Jain Manish Kumar and Jeyaseelan, A. T., A study and implications on the potential of satellite image spectral to assess the iron ore grades of Noamundi iron deposits area. J. Geol. Soc. India, 2018, 91, 227-231.

9. Crowley, J. K., Brickey, D. W. and Rowan, L. C., Airborne imaging spectrometer data of the Ruby Mountains, Montana: mineral discrimination using relative absorption band-depth images. Remote Sensing Environ., 1989, 29, 121-134.

10. Nikolakopoulos, K. G., Tsombos, P. I., Photiades, A., Psonis, K. and Zervakou, A., Using remote sensing multispectral data and GIS techniques for the geological mapping of Halki Island. Bull. Geol. Soc. Greece, 2013, 47, 1500-1509.

11. Zahra Yazdi, Ali Reza Jafari Rad and Kimiya Sadat Ajayebi, Analysis and modeling of geospatial datasets for porphyry copper prospectivity mapping in Chahargonbad area, Central Iran. Arab. J. Geosci., 2015, 8, 8237-8248.

12. Van Der Meer, F., Analysis of spectral absorption features in hyperspectral imagery. Int. J. Appl. Earth Obs. Geoinf., 2004, 5, 55-68.

13. Han, T. and Nelson, J., Mapping hydrothermally altered rocks with Landsat 8 imagery: A case study in the KSM and Snow field zones, northwestern British Columbia. British Columbia Geol. Surv., 2015, 103-112.

14. Mwaniki, M. W., Moeller, M. S. and Schellmann, G., A comparison of Landsat $8(\mathrm{OLI})$ and Landsat $7(\mathrm{ETM}+)$ in mapping geology and visualising lineaments: a case study of central region Kenya. Int. Arch Photogramm. Remote Sens. Spat. Inf. Sci., 2015, 40, 897.

15. Roy, D. P. et al., Landsat-8: Science and product vision for terrestrial global change research. Remote Sensing Environ., 2014, 145, $154-172$.

16. Geological Quadrangle Map (Jamshedpur Quadrangle, Bihar, Orissa and West Bengal) of Geological Survey of India.

17. Dunn, J. A., Geology and petrology of Eastern Singhbhum and surrounding areas. Mem. Geol. Surv. India, 1942, 69, 261-456.

18. Agus, A. J. L., Mapping white mica in milled porphyry copper pebbles using hyperspectral imagery: an exploratory study. GeoInf. Earth Obs., 2011, 26-28.

19. Anon, GSI, ER, Unpublished GSI report on Project Singhbhum Synthesis of data of Singhbhum Copper Belt, Singhbhum District, Bihar: Part I \& II, Unpublished, 1991.

20. Banerjee, K., Panda, S. and Kumar Jain, M., Identification and mapping of copper mining area in Singhbhum copper belt using advance image processing techniques. Int. J. Sci. Res., 2012, 1404-1407.

21. Pal, D. C., Sarkar, S., Mishra, B. and Sarangi, A. K., Chemical and sulphur isotope compositions of pyrite in the Jaduguda $\mathrm{U}(-\mathrm{Cu}-\mathrm{Fe})$ deposit, Singhbhum shear zone, eastern India: implications for sulphide mineralization. J. Earth Syst. Sci., 2011, 120, 475-488.

22. Bhattacharya, C., Talapatra, A. and Bose, S. S., Integrated geochemical approach for tracing gold mineralisation in parts of Singhbhum and Ranchi Districts, Bihar, India. Rec. Geol. Surv. India, 1984, 114, 1-14; https://eurekamag.com/research/019/214/ 019214244.php

23. Sarkar, S. N., Pre-cambrian Stratigraphy and Geochronology of Peninsular India, Dhanbad Publishers, India, 1968, vol. 33.

24. Banerji, A. K., Ore genesis and its relationship to volcanism, tectonism, granitic activity, and metasomatism along the Singhbhum shear zone, eastern India. Econ. Geol., 1981, 76, 905-912. 
25. National Aeronautics and Space Administration; http://science. nasa.gov/missions/ldcm/ (accessed on 18 February 2017).

26. Prost, G. L., Remote Sensing for Geologists: A Guide to Image Interpretation, CRC Press, 2002, 2nd edn.

27. Miyatake, S., Regional Lineament analysis and alteration mineral mapping for intrusive related copper exploration in the Myanmar central volcanic belt. Proc. 23rd Asian Conf. on Remote Sensing, 2002, pp. 1-4 (CD-ROM).

28. Pour, A. B. and Hashim, M., Alteration mineral mapping using ETM+ and hyperion remote sensing data at Bau Gold Field, Sarawak, Malaysia. In IOP Conference Series: Earth Environ. Sci., 2014, 18, 12-149.

29. Ren, D. and Abdelsalam, M. G., Optimum index factor (OIF) for ASTER data: examples from the Neoproterozoic Allaqi Suture, Egypt. Proc. Geol. Soc. Am., 2001, p. 123.

30. Ali, A. S. and Pour, A. B., Lithological mapping and hydrothermal alteration using Landsat 8 data: a case study in ariab mining district, red sea hills, Sudan. Int. J. Basic Appl. Sci., 2014, 3, 199.

31. da Cunha Frutuoso, R. M., Mapping hydrothermal gold mineralization using Landsat 8 data. A case of study in Chaves license, Portugal, 2015.

32. Pour, A. B. and Hashim, M., Regional hydrothermal alteration mapping using Landsat-8 data. In Space Sci. Commun. (Icon Space), Int. Conf., 2015, 199-202.

33. Ducart, D. F., Silva, A. M., Toledo, C. L. B. and Assis, L. M. D., Mapping iron oxides with Landsat-8/OLI and EO-1/Hyperion imagery from the Serra Norte iron deposits in the Carajás Mineral Province, Brazil. Braz. J. Geol., 2016, 46, 331-349.

34. Arunachalam, M., Udhayaraj, A. D., Jacob, A., Naren Prabakaran, V. P., Vasanth, M. S. and Saravanavel, J., Hydrothermal Mineral Alteration Mapping in parts of Northwestern Tamil Nadu, Indiausing Geospatial Technology. Int. Symp. Oper. Remote Sens., 2014.

35. Liew, S. C., Principles of Remote Sensing-Centre for Remote Imaging, Sensing and Processing, CRISP, 2001.

36. Goetz, A. F. and Rowan, L. C., Geol remote sensing. Science, 1981, 211, 781-791.

37. Rowan, L. C. and Mars, J. C., Lithologic mapping in the Mountain Pass, California area using advanced spaceborne thermal emission and reflection radiometer (ASTER) data. Remote Sens. Environ. 2003, 84, 350-366.

38. Mohan, B. K. and Porwal, A., Hyperspectral image processing and analysis. Curr. Sci., 2015, 108, 833-841.

39. Clark, R. N., King, T. V., Klejwa, M., Swayze, G. A. and Vergo, N., High spectral resolution reflectance spectroscopy of minerals. J. Geophys. Res. Solid Earth, 1990, 95, 12653-12680.
40. Mars, J. C. and Rowan, L. C., Regional mapping of phyllic-and argillic-altered rocks in the Zagros magmatic arc, Iran, using Advanced Spaceborne Thermal Emission and Reflection Radiometer (ASTER) data and logical operator algorithms. Geosphere, 2006, 2, 161-186.

41. Clark, R. N. et al., Surface reflectance calibration of terrestrial imaging spectroscopy data: a tutorial using AVIRIS. Proc. 10th Airb. Earth Sci. Works, 2002, pp. 1-2.

42. Mukerji, B. and Sarkar, B. C., An integrated GIS modeling approach to mineral potential mapping of copper deposits of Singhbhum belt, India. Appl. Comput. Oper. Res. Miner. India, 2005, 235-245.

43. Clark, R. N., Spectroscopy of rocks and minerals, and principles of spectroscopy. Manual Remote Sensing, 1999, 3, 3-58.

44. Soe, M., Kyaw, T. A. and Takashima, I., Application of remote sensing techniques on iron oxide detection from ASTER and Landsat images of Tanintharyi coastal area, Myanmar. Eng. Resour. Sci. Res. Rep., 2005, 26, 21-28.

45. Zhang, T. et al., Integrating data of ASTER and Landsat-8 OLI (AO) for hydrothermal alteration mineral mapping in Duolong Porphyry $\mathrm{Cu}-\mathrm{Au}$ deposit, Tibetan Plateau, China. Remote Sensing, 2016, 8, 890.

46. Ben-Dor, E., Kruse, F. A., Lefkoff, A. B. and Banin, A., Comparison of three calibration techniques for utilization of GER 63channel aircraft scanner data of Makhtesh Ramon, Negev, Israel. Photogramm. Eng. Remote Sens., 1994, 60, 1339-1354.

47. Brown, A. J., Walter, M. R. and Cudahy, T. J., Hyperspectral imaging spectroscopy of a Mars analogue environment at the North Pole Dome, Pilbara Craton, Western Australia. Aust. J. Earth Sci., 2005, 52, 353-364.

48. Pour, A. B. and Hashim, M., Hydrothermal alteration mapping from Landsat-8 data, Sar Cheshmeh copper mining district, southeastern Islamic Republic of Iran. J. Taibah Univ. Sci., 2015, 9, $155-166$.

ACKNOWLEDGEMENTS. We would like to express our sincere and warm gratitude to all people who contributed to this research work: $\mathrm{Dr}$ Sarvesh Chandra Katiyar, Sukrit Dey and Atanu Bandopadhyay. We thank Govt of India, Jharkhand Space Applications Centre (JSAC), RRSC-East, ISRO and MoEF\&CC, Dehradun for support.

Received 16 October 2017; revised accepted 15 February 2019

doi: $10.18520 / \mathrm{cs} / \mathrm{v} 116 / 110 / 1639-1647$ 